International Research Journal of Engineering, IT \& Scientific Research
Available online at https://sloap.org/journals/index.php/irjeis/
Vol. 5 No. 5, September 2019, pages: 8 15
ISSN: 2454-2261
https://doi.org/10.21744/irjeis.v5n5.723

\title{
Learning Problems on Brain Disorders
}

\begin{tabular}{l} 
Article history: \\
\hline \\
Received: 09 January 2019 \\
Accepted: 31 July 2019 \\
Published: 28 August 2019 \\
\end{tabular}

\section{Keywords:}

education;

intervention;

learning difficulty;

learning;

pedagogic;
Elvira Judith Mero Chávez ${ }^{\text {a }}$ Willian Liborio Delgado Pibaque ${ }^{b}$ Washington Javier Mero Chávez ${ }^{\mathrm{c}}$ María Mercedes López López ${ }^{\mathrm{d}}$

\begin{abstract}
The learning problems have aimed at identifying the disorders or disorders of the brain, that has perceived as conflicts of the cognitive system prevent the acquisition of significant knowledge. Among the most frequent problems are mentioned three: Dyslexia, dysgraphia, and dyscalculia that make it impossible for students to increase reading, writing and mathematical processes, causing disadvantages in the development of skills and abilities. The need for teachers in pedagogical interventions has raised, since they work in conjunction with psychologists and psychologists in order to take control from the detection of a problem and progress, identifying weaknesses and strengths that facilitate the proper application of pedagogical techniques and methods. The methodology applied in this investigation was inductivedeductive, emphasizing the study of problems from the particular to the general and included techniques such as survey, interview, control cards, and observation card. This will have a significant impact on society as critical, analytical and reflective students have formed, who develop in the educational, family and social environment.
\end{abstract}

2454-2261 ${ }^{\circledR}$ Copyright 2019. The Author. This is an open-access article under the CC BY-SA license (https://creativecommons.org/licenses/by-sa/4.0/) All rights reserved.

\section{Author correspondence: \\ Elvira Judith Mero Chávez, \\ Master in Innovation in Education, Pontificia Universidad Católica del Ecuador. \\ Email address: emero1333@pucem.edu.ec}

\section{Introduction}

The human being in an environment where he develops learns throughout his life. The present investigation has as purpose to know the problems of learning and the pedagogical intervention.

The problems of learning are difficulties that students show when they acquire knowledge, develop skills and abilities and make it difficult to understand, organize and store information, this can have repercussions such as

\footnotetext{
a Pontificia Universidad Católica del Ecuador, Quito, Ecuador

${ }^{\mathrm{b}}$ Unidad Educativa Fiscal Costa Azul, Manta, Ecuador

${ }^{c}$ Unidad Educativa Replica Manta, Manta, Ecuador

${ }^{\mathrm{d}}$ Unidad Educativa Fiscal Costa Azul, Manta, Ecuador
} 
school failure. Each individual is different and learns differently, knowing that some learn faster than others and others through practice or base knowledge through theory.

It is necessary to know the learning of each student, taking into account the individual differences that refers to the potential, diversity of skills, abilities, talents and ways of learning, in such a way that teachers can guarantee a pedagogical intervention according to the needs that students with learning difficulties have, and will allow applying in an accurate manner; methodologies and didactic strategies to improve the perception, hearing, vision, and memory and in this way develop the capacities and skills that are useful in the society of the 21 st century (Alava \& Martinez, 2019; Macías et al., 2018).

With the above qualities it is intended that children develop knowledge and strengthen learning, through innovative techniques, methods and strategies that lead to significant appropriation of knowledge and learning to learn and learn to think, while the use of technological tools such as the internet provides a variety of pedagogical tools that activate motivation and interest in discovering a different world of information and challenges in learning.

Teachers must adhere to pedagogy, to study the evolution of education over time and the positive changes that help improve the educational context. They are trained to make educational improvements, since the knowledge will allow them to work together with the experts in detecting and diagnosing learning problems; as are the psychologists and psychologists, without leaving behind the fundamental pillar that are the parents, who assume the challenge of reinforcing and guiding these students from the homes (Mendoza et al., 2019; Pérez et al., 2018).

The pedagogical intervention requires individualized and multidisciplinary attention in the teaching-learning processes and is directed in order with, by and for the learner, being the teacher's task, to know about the causes of the problem and the conditions where they develop as the environment plays a necessary role in learning, in behavior, and in emotions. The learning disorders most present are dyslexia, dysgraphia, and dyscalculia.

The following investigation allowed to know, analyze and observe the improvements in the academic, personal and social development of the students.

\section{Materials and Methods}

In this research the inductive and deductive method was applied, using direct observation in the detection of learning problems, working simple knowledge to the most complex, where readings, writings, dictations, sentence formulation, dramatizations, and exhibitions were evidenced, and the deductive method was addressed in the resolution of the dyscalculia, due to the fact that objective was set and methodologies were developed according to the development of thought, ranging from the general to the particular (Suarez et al., 2019).

In addition, educational needs detection cards were used, where the level of knowledge learned by the students, attention, and behavior was observed, as well as a control record was applied to follow the progress of the learning obtained during a period of time. determined period, the interview and the survey of the legal representatives of the students by the group of psychologists and psychopedagogues, where joint work was organized to improve performance and learning. The sample that was applied in this research is qualitative taking its own criteria, in order to investigate the problems encountered.

\section{Results and Discussions}

Learning is the acquisition of enriching knowledge that human beings have, through which they develop skills, skills, behaviors, and knowledge, it is intended that students apply processes such as identification, accommodation, assimilation, and interpretation of data that lead to significant learning and durable. The knowledge is acquired in an empirical way that is through experiences and rationally through the sources of knowledge as texts, allow the delight of knowing, doing things well, and be able to share with other beings new experiences of how to expand knowledge.

Learning is a knowledge acquired throughout life, with the purpose that students develop potential autonomously, consciously and meaningfully. Demonstrating an effective academic development that allowed them to seek different resolutions in everyday problems (Gutiérrez, 2018).

The diversity of skills and abilities allow learners to develop knowledge and share strengths as student guides with those who have difficulty since each student has different learning styles and for this, teachers must identify

Chávez, E. J. M., Pibaque, W. L. D., Chávez, W. J. M., \& López, M. M. L. (2019). Learning problems on brain disorders. International Research Journal of Engineering, IT \& Scientific Research, 5(5), 8-15.

https://doi.org/10.21744/irjeis.v5n5.723 
weaknesses, strengths and academic reinforcement programs with curricular adaptations, according to the difficulty, looking for alternative solutions. As shown in Figure 1. Acquisition of knowledge.

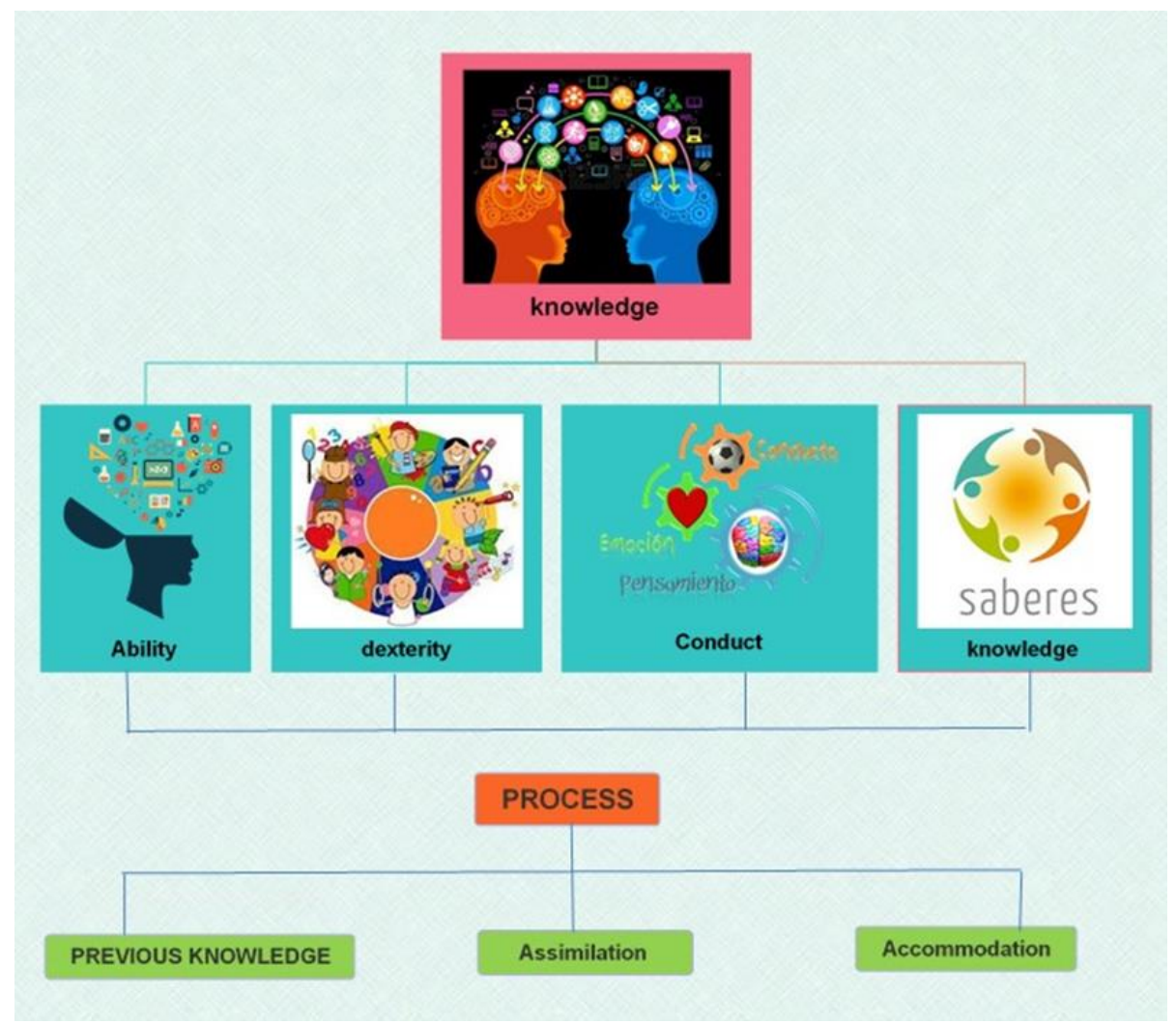

Figure 1. Acquisition of knowledge

The knowledge allows learners to modify skills, skills, behavior, and knowledge that through time are developed through assimilation and accommodation processes, acquiring significant concepts

\subsection{Learning difficulties}

The problem ends is described as difficulties in the psychological processes that affect: the fluency of speaking, in order words, sentences and sentences. In the domain of mathematics, unfavorable works are perceived in calculations and reasoning due to disorders or damages of the brain system as perceptual disabilities (Reyes, 2013).

It is stated that the problems of learning are intellectual disorders that affect learners, due to many circumstances that prevent them from learning at the same pace as other students, these problems are not mental delays but vary in level according to the needs of the learner. There are several learning problems that cause distortion of writing, calligraphy, inadequate reading, inconsistencies in mathematical calculations that prevent learners from developing skills, abilities, and potentialities at the same pace as others (Escribano, 2018).

Teachers must eliminate inequality barriers giving priority to the group and individual work that supports the development of skills and qualities in students, opting for inclusion, participation and individualized learning. For the 21 st century, students must be able to develop in different areas of society so that they can express themselves with fluency and coherence. Disorders such as dyslexia occur in children with normal learning abilities and have a negative influence on text reading, causing learners to be late, confusing letters when writing or distorting syllables (Acero, 2018).

The learning involves reading and writing skills that allow developing knowledge through the use of different learning techniques such as synthesis, analysis, conceptual maps, mind facts, oratory, among others, which are academic activities that can be successfully developed if detects a difficulty of this kind in time. 


\section{Dyslexia and dysgraphia}

In specific relation between dyslexia and dysgraphia, it is observed that they intervene prejudicially in learning, preventing the development of written and verbal language. Dysgraphia is presented as a learning disorder in writing, meaning that children do not correctly address writing, do not use the lines of notebooks properly, distort letters, change uppercase and lowercase letters, vary handwritten letters and print letters, as a consequence of the aforementioned students have language delays, visual problems, insufficient motor development, poor fluency in speech, inadequate control of the brain and memory (Cema \& Castillero, 2018).

Considers that there are several signals that are detectable to identify this learning problem that affects various areas of development and for this, the teachers regulate the school environment with flashy and innovative didactic materials in order that the students feel safe, accepted and pleasant to the time to learn.

\section{Dyscalculia}

Mathematical problems make it difficult for learners to work with numbers. Dyscalculia is presented as cognitive alterations in the incomprehension of mental calculations, making difficult the development of memory, logic, reasoning, spatial location, transcription of numerical texts and confusion of mathematical operations, tend to feel apathy and disinterest for this matter since the teacher uses learning methodologies outdated and few motivating learning, making the learning environment becomes monotonous and boring, for this it is advantageous to apply games that awaken interest in this area and encourage students to believe their own learning through videos, games, exhibitions, riddles, and research (Tenecela \& Abad, 2014).

Mathematics is very complex and there is a need to intervene with mechanisms that facilitate the development of perception, reasoning, and attention, such as the use of the inductive-deductive method that encompasses pedagogy and teaching from the simple to the difficult, achieving a taste for the numbers and the mathematical calculations.

Educators establish goals and objectives with the purpose of acquiring commitments and skilfully routing an intentional work that is deployed with, by and for the learner allowing to discover appropriate behaviors and with the purpose of advancing cognitive development acquired (Touriñan, 2011).

\subsection{Pedagogical}

The orientation in the educational institutions is adequate to apply individualized treatments that allow the students to face the difficulties and face in an efficient and effective way the diverse learning. In order to have information, students' clinical data and evolution must be gathered, as the problem has progressed since the detection, treatment, how it affects the behavior and how it develops in the family and social environment, standardized tests for parents are needed and teachers that allow the exact identification of the problem or attention deficit and hyperactivity disorders; as well as the level of withdrawal, anxiety revelation of the behavior and the deficiencies associated with readings, writings and mathematical problems (Abad et al., 2013).

Taking into consideration this research, it is recommended that teachers obtain accurate and necessary information about the students with learning difficulties using control cards to verify the students' progress and identify the flaws and inconsistencies that will allow the development of didactic instruments and plans adapted to the cognitive conflicts that are identified in the students. Executing relevant adjustments in the teaching-learning processes allows developing skills, aptitudes, and knowledge that strengthen the integral development of the students, making them critical, analytical, reflective and useful towards society.

\subsection{Constructivism}

The theoretical foundation of this learning highlights that the cognitive part of learners are acquired spontaneously with the interaction of the environment plan to apply the constructivist theory of Jean Piaget where the purpose is to produce knowledge through interaction with the real environment, where the students learn significant knowledge that allows them to develop in society and solve problems. There is the talk of how the student creates learning, using resources available from the environment, technological or innovative, and not how much he learns since the amount of knowledge he possesses has not measured, but rather what is necessary and useful for life (Saldarriag et al., 2016).

Recognize that learners are transforming entities of a just and egalitarian society. That seek to improve living conditions at a personal and economic level, teachers must deal with preparing children and young people in a

Chávez, E. J. M., Pibaque, W. L. D., Chávez, W. J. M., \& López, M. M. L. (2019). Learning problems on brain disorders. International Research Journal of Engineering, IT \& Scientific Research, 5(5), 8-15.

https://doi.org/10.21744/irjeis.v5n5.723 
constructivist way promoting autonomy, research and work as a team where they are the authors of their own learning and take entrepreneurial initiatives that lead them to success.

\subsection{Education and fundamental pillars of educational}

The institutions prepare students to function in different areas of life, which is why in this 21 st-century era it is feasible to use the fundamental pillars in education as the fundamental basis of all learning (Reyero, 2018), As can be seen in figure 2. Fundamental pillars of education

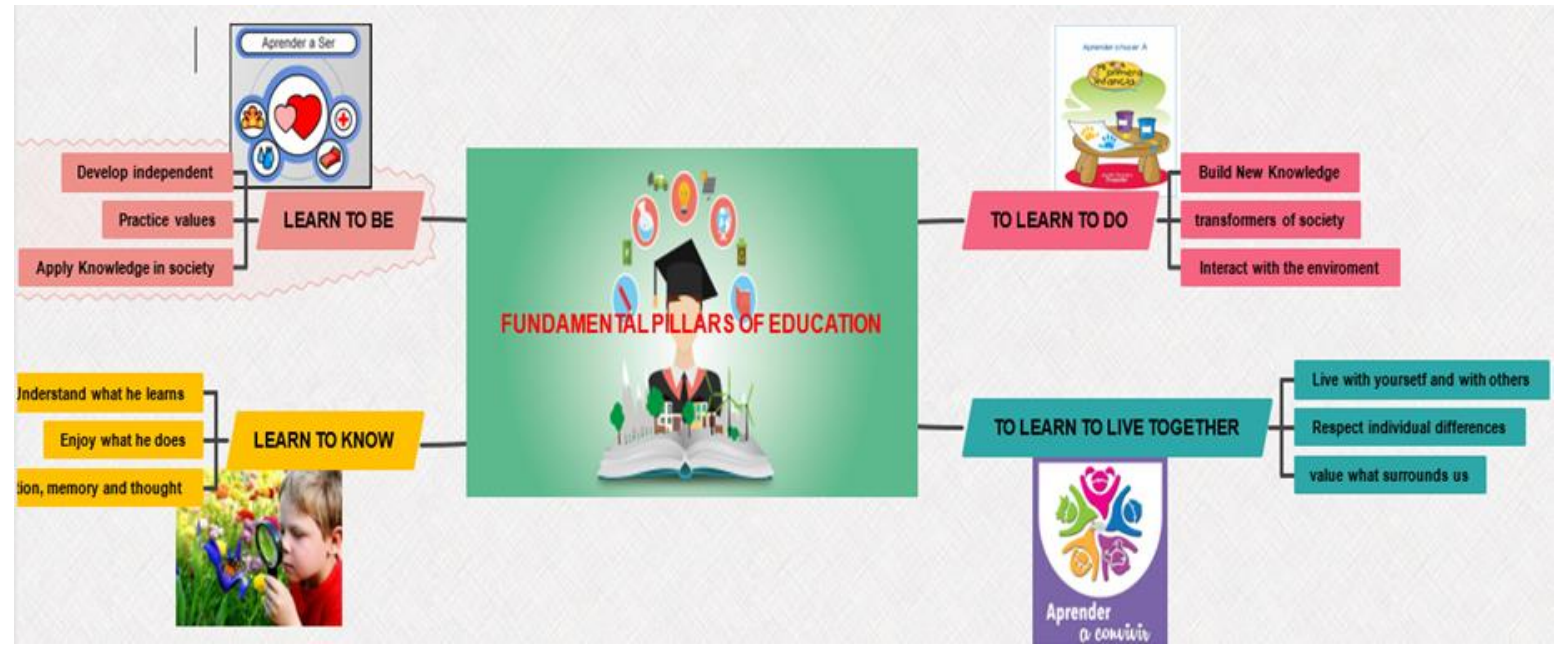

Figure 2. Fundamental pillars of Education

LEARNING TO BE. In the course of time, the human being prepares autonomously to be a transformative entity of change; cognitive, affective, emotional, personal and social, being transmitters of knowledge and values. Thanks to the constructive practices of knowledge, it manages to adapt to society without problems and develops in a global way.

LEARNING TO DO. It requires knowledge to know, they are two pillars that are linked to meaningful knowledge, it is the perfect combination of theory and practice. Knowing how to do involves the practice of scientific knowledge, allowing learners to work in teams, develop personal skills and have a broad vision of professional goals for the good of society.

LEARNING TO KNOW. Knowledge implies understanding the world in which it develops, the challenges and the advantages. Understand what they learn and enjoy what they do, discover favorable spaces where students interact, discover, create and share learning learn to apprehend, in an analytical, reflective and critical way.

LEARNING TO LIVE TOGETHER. Value the environment where you live, live in harmony, peace, solidarity, accepting yourself and others, respecting different cultures, languages, cultures, and religions.

The learning problems have framed in the learning difficulties presented by different students, which implies fostering pedagogical intervention for the treatment of these difficulties.

The strategies used in the teaching of dyslexia, dysgraphia, and dyscalculia are what have allowed work. In the school setting with other colleagues inside and outside the classrooms, achieving dynamic integration in: games, exhibitions, riddles, songs, rehearsals, dramatizations, reflexive readings, individual and group readings; also mathematical games like soup of numbers, resolution of problems, contests of which KNOWS KNOWS, works of paintings inculcating creativity, authenticity, and domain of subjects. The teacher leads the teaching and applies techniques and methods of teaching and learning according to the needs of students with learning difficulties.

It is necessary that the theories of different authors define that learning problems have focused on different approaches to learning, the constructivist as a fundamental part of knowledge where teachers are guides of learning lessons, being the student's authors of their own knowledge. 
The pedagogical intervention strengthens the development of students' cognitive abilities since it is carried out jointly with psychologists, psychologists and parents, who create appropriate learning environments, which allows them to adapt to a climate of trust, where fears to learn are forgotten and choose to enjoy and love what they do.

\section{Conclusion}

In the present investigation on learning problems and pedagogical intervention, it allows to know the most common difficulties that affect the students' learning, identify them and implement appropriate, motivating strategies that allow developing the differentiated abilities of the students, in addition, the constructivist pedagogy contributes that students learn to learn, that are autonomous and protagonists of their own learning, where the essential dynamic is the appropriation of knowledge that will last throughout life, and at the same time will allow them to be critical, analytical and reflective with an open mind and visionary towards personal and social development.

Conflict of interest statement and funding sources

The authors declared that they have no competing interest.

Statement of authorship

The authors have a responsibility for the conception and design of the study. The authors have approved the final article.

\section{Acknowledgments}

Dedicate my sincere thanks to my Mother and family the patience and motivation provide to move forward to giving me the necessary support to grow.

Chávez, E. J. M., Pibaque, W. L. D., Chávez, W. J. M., \& López, M. M. L. (2019). Learning problems on brain disorders. International Research Journal of Engineering, IT \& Scientific Research, 5(5), 8-15. 


\section{References}

Abad-Mas, L., Ruiz-Andres, R., Moreno-Madrid, F., Herrero, R., \& Suay, E. (2013). Psychopedagogical intervention in attention deficit hyperactivity disorder. Revista de neurologia, 57, S193-203.

Acero, M. (2018) . Causes of learning problems in students of the fourth year of general basic education at the Luis Napoleón Dillon School, academic year: 2018 - 2019. (Undergraduate thesis) Universidad Politécnica Salesiana, Cuenca, Ecuador.

Alava, E. E., \& Martinez, M. E. M. (2019). Impact of teaching-learning process for brain. International Journal of Health Sciences, 3(1), 33-40. https://doi.org/10.29332/ijhs.v3n1.304

Cema, A., \& Castillero, L. (2018). Relationship between dysgraphia and emotional indicators in primary school students, Lima, 2015. (Master thesis) César Vallejo University, Lima, Peru.

Escribano, I. (2018). Intervention program for learning difficulties. (Master's Thesis). University of Jaume I, Castellón, Spain.

Gutiérrez, M. (2018). Learning styles, strategies to teach. Its relationship with emotional development and "learning to learn". Pedagogical Trends Magazine, 83-96.

Macías, E. I. P., Cedeño, H. A. C., \& Chávez, G. M. R. (2018). Importance of Improving Resilience in TeachingLearning Process of Students with Disabilities. International Research Journal of Management, IT and Social Sciences, 5(2), 120-128.

Mendoza, L. R. M., Martinez, M. E. M., \& Suarez, A. M. S. (2019). The brain as a fundamental axis in learning process. International Research Journal of Engineering, IT \& Scientific Research, 5(4), 38-45. https://doi.org/10.21744/irjeis.v5n4.689

Pérez, A. V., Gámez, M. R., Briones, V. F. V., Viteri, C. G. V., \& Molina, L. A. V. (2018). Sustainable development seen from environmental training in university linkage. International Journal of Life Sciences, 2(1), 12-20. https://doi.org/10.29332/ijls.v2n1.75

Reyero, M. (2018). Constructivist education in the digital era. Magazine Technology, science and education, 111127.

Reyes, D. (2013). Academic learning problems in adolescents from 11 to 15 years of the San Lorenzo Educational Unit, rural Parish of the city of Manta, during the period January to June 2013. (Undergraduate thesis). Laica Eloy Alfaro University of Manabi, Manta, Ecuador.

Saldarriaga, W., Lein, P., Teshima, L. Y. G., Isaza, C., Rosa, L., Polyak, A., ... \& Tassone, F. (2016). Phenobarbital use and neurological problems in FMR1 premutation carriers. Neurotoxicology, 53, 141-147. https://doi.org/10.1016/j.neuro.2016.01.008

Suarez, A. M. S., Martinez, M. E. M., \& Mendoza, L. R. M. (2019). Brain and learning. International Journal of Social Sciences and Humanities, 3(2), 128-135. https://doi.org/10.29332/ijssh.v3n2.302

Tenecela, J., \& Abad, K. (2014). Incidence of learning difficulties (dyslexia and dyscalculia) in students from third to seventh year of basic general education. Ecuador basin. Obtained from http: // dspace. ucuenca. edu. ec / bitstream / 123456789/20328/1 / THESIS. pdf.

Touriñán-López, JM (2011). Keys to approach artistic education in the educational system: education "for" the arts and education "for" an art. 


\section{Biography of Authors}

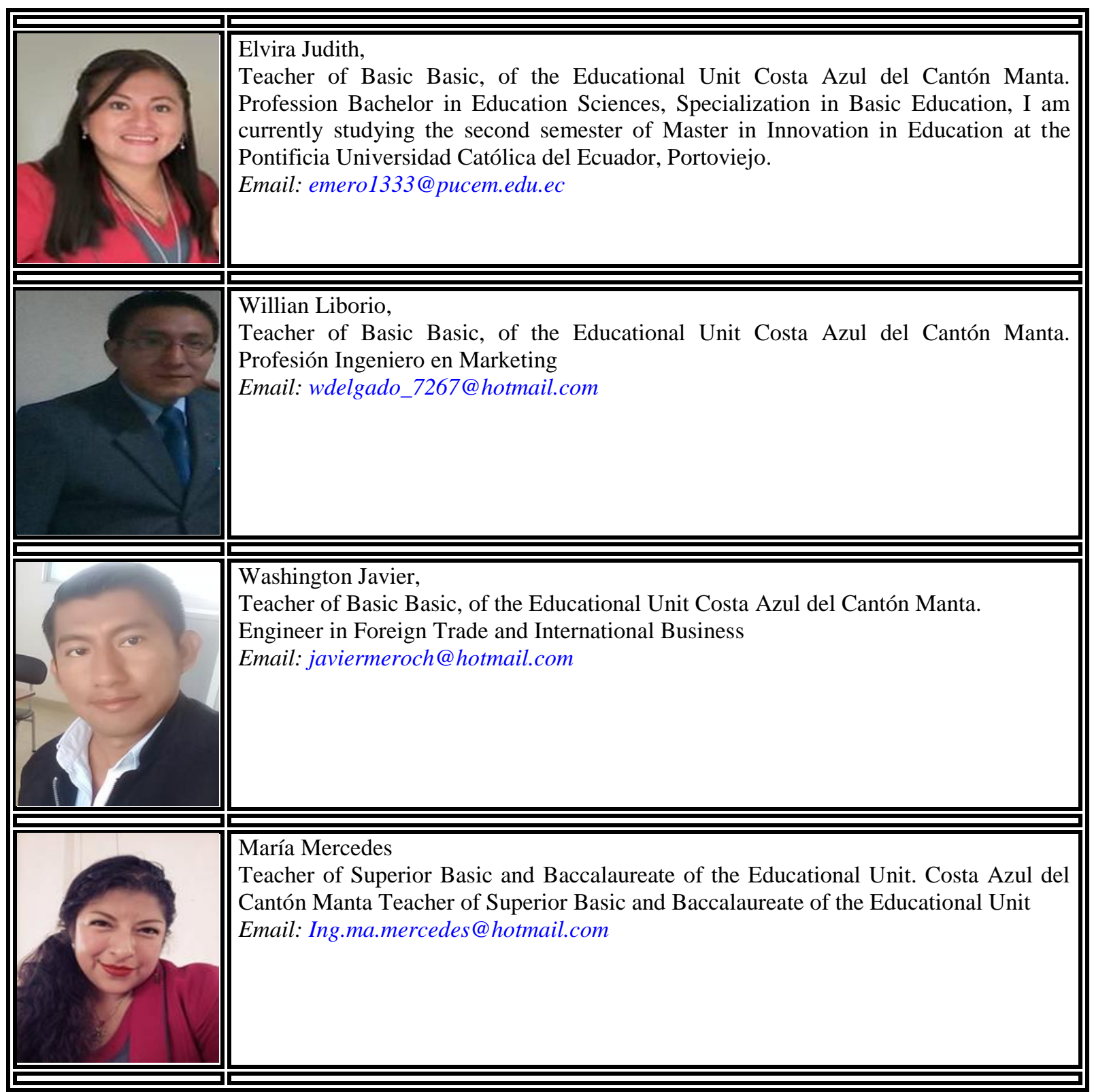

Chávez, E. J. M., Pibaque, W. L. D., Chávez, W. J. M., \& López, M. M. L. (2019). Learning problems on brain disorders. International Research Journal of Engineering, IT \& Scientific Research, 5(5), 8-15. 